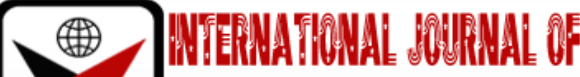

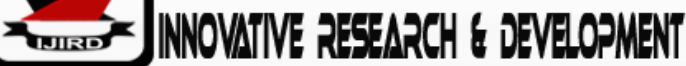

ISSN 2278 - 0211 (Online)

\section{Influence of Chemistry Teachers' Self-Efficacy on Inclusive Education in Secondary School Chemistry Classroom Teaching in Anambra State, Nigeria}

\begin{tabular}{|c|}
\hline Okonkwo, Ifeoma G. \\
Lecturer, Department of Science Education, \\
Nnamdi Azikiwe University, Awka, Nigeria \\
Samuel, N.N.C \\
Lecturer, Department of Science Education \\
Nnamdi Azikiwe University, Awka, Nigeria
\end{tabular}

\begin{abstract}
:
This study investigated the influence of chemistry teachers' self-efficacy on inclusive education in secondary school chemistry classroom teaching in Anambra state, Nigeria. Age and gender of the teachers were considered as being among factors that determine self-efficacy, hence were also investigated. Three research questions and two null hypotheses guided the study. Descriptive survey research design was adopted for this study. The entire population of chemistry teachers in the state which is made up of two hundred and sixty-five Chemistry teachers was used as the sample for the study. An instrument Teachers' Efficacy to Implement Inclusive Education (TEIIE) was adopted from Kielblock (2018) and modified to suit the environment and cultural setting. Due to the modifications, the reliability of the instruments was re-established using Cronbach alpha and a coefficient of 0.79 was obtained. Means, Standard Deviation, Percentages, and One-way ANOVA were used to analyze and interpret data obtained. The result of the study revealed that gender has a significant influence on self-efficacy of teachers. Females had higher self-efficacy than males. Age was equally significant with the younger teachers having higher self-efficacy than the older teachers. The educational implications of the findings were discussed and based on the findings; some recommendations were made.
\end{abstract}

Keywords: Teachers' self-efficacy, inclusive education, classroom teaching, chemistry

\section{Introduction}

Heterogeneity within a group is as naturally unavoidable as it's oftentimes desirable, while differences in ability are not the yardstick for measuring an individual's worth. An understanding of the afore mentioned facts among other factors may have formed the philosophical basis for inclusive education. Mundy (2016) informed that the idea of 'education for all was laid out in the 1940s after World War II and this was clearly articulated in the constitution of the UNESCO, which was adopted in London in 1945.Similarly, the idea that 'everyone has the right to education was equally articulated by the United Nations General Assembly in Paris (UN, 1948) in article 26 of the Universal Declaration of Human Rights. UNESCO (1990 p1) further repeated that everyone has a right to education'.

The UNESCO declaration states that education is a fundamental right for all people, women and men of all ages throughout the world. Continuing, it clearly states that disparities must be reduced as it pertains to all categories of underserved groups. It emphasized clearly that the learning needs of the disabled demand special attention. Steps need to be taken to provide equal access to education to every category of disabled persons as an integral part of education system' (UNESCO, 1990 p.1). In 1994, a world conference on Special Needs Education was held in Salamanca, Spain and it further reaffirms the Education for all agenda. The Salamanca's report clearly stated that regular schools with this inclusive orientation are the most effective means of combating discriminatory attitudes, creating welcoming communities building an inclusive society and achieving education for all (UNESCO 1994, p. ix). Another world Education Forum held in Dakar, Senegal in 2000, led to the publication of Guidelines for inclusion in 2005 by UNESCO. The guidelines relate the vision of education for all and the vision of inclusive education to each other. According to UNESCO (2005), guidelines for inclusive education for all students can only be achieved when discrimination and exclusory practices are seriously tackled:

It is important to highlight that Education for All (EFA) does not automatically imply inclusion. Inclusion properly understood is precisely about reforming schools and ensuring that every child receives quality and appropriate education within these schools. To this extent inclusion is critical to the Education for All movement since without it, a group or groups of children are excluded from education. Thus, EFA by definition cannot be achieved if these children are excluded. Both EFA and inclusion are about access to 
education, however inclusion is about access to education in a manner that there is no discrimination or exclusion for any individual or group within or outside the school system' (UNESCO 2005, p. 29)

Meanwhile, the United Nations (UN) in 2015, adopted the new sustainable development agenda in which the eight Millennium Development Goals (MDGs) were revised into seventeen Sustainable Development Goals (SDGs). MDG number 2 which hinges on education - 'achieve universal primary education' was rephrased as 'ensure inclusive and quality education for all and promote lifelong learning (SDG.4). However, the World Education Forum 2015 which was held in Incheon, Korea, came up with a declaration in line with SDG.4 that presented a new vision for education until 2030, (UNESCO 2015, p.6.) The Incheon declaration addressed a wide range of issues like inclusion and equity, gender equality, quality education, access to education and lifelong learning opportunities. The declaration clearly pointed out that inclusion and equity entails addressing exclusion and ensuring 'no one is left behind': The Incheon declaration which presents a broad definition of inclusive education, has set the direction until 2030. UNESCO (2005) broadly defined inclusion as

'A process of addressing and responding to the diversity of needs of all learners through increasing participation in learning, cultures and communities and reducing exclusion within and from education. It involves changes and modifications in content, approaches, structures and strategies, with a common vision which covers all children of the appropriate age range and a conviction that it is the responsibilities of the regular system to educate all children (p.12).

Inclusion according to Okuoyibo (2001) as cited in Oluka (2014) means bringing students with disabilities (regardless of the nature and severity) into all placement activities of general education such as schools, classrooms and the surrounding communities. Continuing he stated that children with disabilities should be unconditionally mainstreamed into the regular education system irrespective of the nature and severity of their disabilities. In this study, the researchers view inclusive education as one that ensures all learners, regardless of disability, gender, race, socioeconomic class, ethnicity, language, religion, are educated in the school/classroom/community, can participate in all class experiences and as much as possible, in the same manner as everyone else- entirely void of discriminatory or exclusory practices.

The success of any educational program, largely depends on the pivotal role of teachers. Teacher quality and quality teaching are as important as they are indispensable for quality educational outcomes. In realization of this fact, UNESCO (1990) world Declaration on inclusive education frame work of action explicitly highlighted the importance of teachers for the achievement and success of inclusive education when it clearly stated that: the prominent role of teachers as well as other educational personnel in providing quality basic education needs to be recognized and developed to optimize their contribution. Teachers are by this considered as 'key factors' for effective implementation of an education that is inclusive for all.

Students spend not less than eight hours in school with their teachers. The school therefore is a crucial institution for the implementation of inclusive education due to its significance to the students. It provides the space where conceptual ideas of inclusive education need to be exchanged or switched into real world teaching practices and social actions free from discriminations and exclusion. It takes a teacher to make this happen. Through teachers' excellence in teaching, teachers allow for the presence, participation and achievement of all learners in their classroom and through a reflective set of procedures, effective teachers will be able to uncover exclusion and marginalization and adopt strategies to tackle them at least at the classroom level.

Albert Bandura, the original proponent of self-efficacy says it is a personal judgement of 'how well one can execute courses of action required to deal with prospective situations' containing many ambiguous, unpredictable and often times, stressful elements (Bandura \& Schunk 1981, p587). Self-efficacy refers to an individual's belief in his/her ability to execute behaviors necessary to produce specific performance attainments or outcomes. It is a reflection of one's confidence in his/her ability to exert control over motivation, behavior and social environment.

It is the optimistic self-belief and confidence in one's competence or ability of successfully accomplishing a task and producing a favorable result (Akhtar, 2008). Self-efficacy plays a major part in determining our chances, success and oftentimes, according to Miriam (2008), rated above talent in the recipe for success. Self-efficacy develops as a result of information from five types of resources namely, mastery experience, vicarious experience, verbal experience, emotional or psychological state and imaginal experience (Maddux,2005). Self-efficacy is not synonymous in meaning with skill acquisition. Therefore, confidence or self-efficacy that a person has in performing a behavior is a crucial determinant of the person's willingness to engage in a specific behavior. Researchers, Domenech-Betoret, (2017), Triantoro (2013) reported a positive relationship between high efficacy and enhanced academic performance and service delivery. Therefore, the need arises to investigate the Chemistry teachers' self-efficacy in inclusive education and how it influences their behaviors, actions and conditions in the environment, hence this study. Another factor that may likely influence the self-efficacy of Chemistry teachers towards inclusive education is gender.

Gender is a socio-cultural attribute which differentiates feminine from masculine (Imoko 2004 as cited in Okonkwo 2012). Gender is used to describe certain characteristics of men and women which are naturally, culturally and socially determined while those that are biologically determined are regarded as sex. Gender is determined by the tasks, function and roles attributed to men and women in society and in public and private life (v. gender. cawater.info.net retrieved on $27 / 02 / 2020)$.

Gender determines what is expected, allowed and valued in men and women socio-culturally, the benefits ascribed to these roles are created and sustained through traditions, customs, conventions, norms and regulations which are transmitted from generations to generations. How will these gender roles affect Chemistry teachers' self-efficacy in implementing inclusive education? This study answered this question by investigating the influence of gender on the self- 
efficacy of Chemistry teachers towards inclusive education. Furthermore, the teachers chronological age (in years), may also affect their attitude towards inclusive education. This is because, these factors may influence their ease of adopting new educational concepts. The researchers examined these important factors about teachers' background.

\subsection{Statement of the Problem}

UNESCO (2005, p.43) lamented that the pledge made over as far back as 1990 by governments and international development partners to meet the basic learning needs of all children, youths and adults has not been met. The report went further to reveal that close to 60 million children and 70 million adolescents worldwide still do not have access to effective basic education. While children with disabilities are often denied their right to education. The UNICEF monitoring of learning Achievement Study (2011) as cited in Onuigbo (2013) conducted in states in Nigeria (Anambra state inclusive) reported that lack of suitable learning environment is one of the greatest impediments to children attaining literacy and numeracy on basic education. Inadequate classrooms, furniture, equipment and learning materials among others were highlighted. Researchers like Arisar, Reiter \& Layser (2003), Tasmor, Reiter \&Feigin (2005) and Onuigbo (2013) reported that most governments had not adequately prepared for the inclusion of special needs persons into their regular classrooms. Frankal (2010) highlighted the importance of adequate training and skills required to teach students with special needs for the successful implementation of inclusive education programs. In Anambra State, the situation is the same, the provision of such support service especially in the sciences is scarce and, in some places, non-existent. How will this scenario affect the Chemistry teachers' self-efficacy in performing this onerous task of implementing inclusive education?

Teachers are perceived to be an integral component, occupying a critical pivotal position in the successful implementation of inclusive education. It is important to investigate the self-efficacy of teachers towards inclusion of students with disabilities into regular classroom settings, void of necessary support materials and services, because their self-efficacy may influence their behaviors towards and acceptance of such students. Teacher's disposition towards inclusive education will obviously reflect on students' achievement, socialization and skill acquisition among others. Therefore, self-efficacy of Chemistry teachers towards student with special needs could affect their performance and the overall attainment of the goals of the inclusion program. Every student would want to be cared for, socially and emotionally accepted, as an individual in the class. A classroom where derogatory statements and uncomplimentary remarks are made due to a student's failure to respond appropriately to a task will obviously demoralize the child and whip up negative reactions. Against this background, the problem of this study put in question form is what is the influence of Chemistry teachers' self-efficacy on inclusive education in Anambra State. What is the effect of gender and age on chemistry teachers' self-efficacy towards implementation of inclusive education in chemistry classroom teaching in Anambra state?

\subsection{Purpose of the Study}

The study was designed to determine

- The self-efficacy of Chemistry teachers in implementing inclusive education

- The effect of gender on Chemistry teachers' self-efficacy in implementing inclusive education.

- The effect of teachers' age on Chemistry teachers' self-efficacy in implementing inclusive education.

\subsection{Research Questions}

- What is the self-efficacy of Chemistry teachers in implementing inclusive education?

- What is the effect of gender on the self-efficacy of chemistry teachers in implementing inclusive education?

- What is the effect of age on the self-efficacy of chemistry teachers in implementing inclusive education?

\subsection{Hypothesis}

Two null hypotheses were tested at 0.05 level of significance.

- There is no significances difference in the mean self-efficacy scores of male and female Chemistry teachers.

- There is no significant difference in the mean self-efficacy scores of Chemistry teachers due to age

\section{Method}

The descriptive survey research design was adopted in this study. This design explains current situation of an issue or person or event in its natural setting without any form of manipulation. The researchers used the principals of the schools to administer the instruments and then return the completed questionnaires through the office of their zonal directors. The principals and the researchers had earlier met and discussed the distribution of the instrument to their chemistry teachers during their state management meeting. The principals were informed what is required of their Chemistry teachers, thus the consent of the principals was obtained to use their teachers. Furthermore, the researchers gave out their contacts for further clarification if need be. This method totally eliminated item mortality. The researchers attribute this to the fact that the teachers felt it was a government directive and no school wanted to be queried on not filling the questionnaire with every sincerity or not submitting the questionnaire.

\subsection{Population}

The population for the study comprised all Chemistry teachers in all the 265 government owned secondary schools in the six education zones of Anambra State. 


\subsection{Sample and Sampling Technique}

The researchers purposively used the entire population for wider coverage.

\subsection{Instrument for Data Collection}

One instrument was used for data collection. The instrument, Teachers' Efficacy to Implement Inclusive Education (TEIIE) is an 18item instrument adapted from Kielblock (2018).

\subsection{Validity and Reliability of the Instruments}

The instrument was distributed to 30 Chemistry teachers outside the research populations. Data obtained was used to further estimate the reliability of the instruments as a result of modifications made on it. Results yielded 0.79 using Cronbach Alpha.

\subsection{Data Analysis}

Mean, Standard deviation and percentages was used to answer the research questions while the hypothesis were tested using Multivariate Analysis of Variance (MANOVA) and One-Way Analysis of Variance (ANOVA)

\section{Result}

- Research question 1: What is the self-efficacy of Chemistry teachers in implementing inclusive education?

\begin{tabular}{|c|c|c|}
\hline Self-efficacy & Frequency & Percent \\
\hline Low self-efficacy & 96 & 36.2 \\
\hline High self-efficacy & 169 & 63.8 \\
\hline Total & 265 & 100 \\
\hline
\end{tabular}

Table 1: Chemistry Teachers' Self-Efficacy Levels in Inclusive Education Implementation

Table 1 show that $63.8 \%$ of the Chemistry teachers have high self-efficacy in implementing inclusive education while $36.2 \%$ has low self-efficacy. It is clear that more chemistry teachers believe that all students can be accommodated in a chemistry classroom without discrimination.

- Research question 2: What is the effect of gender on the self-efficacy of chemistry teachers in implementing inclusive education?

\begin{tabular}{|c|c|c|c|c|c|}
\hline $\begin{array}{c}\text { Dependent } \\
\text { Variables }\end{array}$ & Gender & Mean & Std. Error & \multicolumn{2}{|c|}{ 95\%Confidence Interval } \\
\cline { 4 - 6 } & & & & $\begin{array}{c}\text { Lower } \\
\text { Bound }\end{array}$ & $\begin{array}{c}\text { Upper } \\
\text { Bound }\end{array}$ \\
\hline Self-Efficacy & Male & 104.764 & 1.928 & 100.965 & 108.562 \\
& Female & 126.043 & 1.582 & 122.927 & 129.159 \\
\hline
\end{tabular}

Table 2: Estimated Marginal Means on Gender

Table 2 shows that females have higher self-efficacy in implementing inclusive education than males as shown by the higher mean score of 126.043 against 104.764 of males. To determine if the difference is significant, Hypothesis 2 was tested at 0.05 level of significance.

- HO 1: There is no significant difference in the Self-efficacy mean scores of male and female Chemistry teachers in implementing inclusive education

\begin{tabular}{|c|c|c|c|c|c|c|}
\hline Source & $\begin{array}{c}\text { Dependent } \\
\text { variable }\end{array}$ & $\begin{array}{c}\text { Type III Sum of } \\
\text { Squares }\end{array}$ & df & Mean Square & F & Sig. \\
\hline Corrected model & Self-Efficacy & $66099.793^{a}$ & 27 & 2448.140 & 19.571 & .000 \\
\hline Intercept & Self-Efficacy & 706079.799 & 1 & 706079.799 & 5644.465 & .000 \\
\hline Gender & Self-Efficacy & 5885.703 & 1 & 5885.703 & 47.051 & .000 \\
\hline Age & Self-Efficacy & 1290.539 & 3 & 430.108 & 3.439 & .018 \\
\hline Gender*Age & Self-Efficacy & 339.083 & 3 & 113.028 & .904 & .440 \\
\hline
\end{tabular}

Table 3: Test of Between-Subject Effects

a. $\quad R$ Squared $=.690$ (Adjusted $R$ Squared $=.655$ )

Result in table 3 shows that the difference between the Self-efficacy mean scores of male and female Chemistry teachers is significant at .000 which is less than 0.05 level of significance. The null hypothesis is therefore rejected.

- Research question 3: What is the influence of Age on the self-efficacy of Chemistry teachers in implementing inclusive education? 


\begin{tabular}{|c|c|c|c|c|c|}
\hline $\begin{array}{c}\text { Dependent } \\
\text { variables }\end{array}$ & Age & Mean & Std. Error & \multicolumn{2}{|c|}{ 95\% Confidence Interval } \\
\cline { 4 - 6 } & & & & Lower Bound & Upper Bound \\
\hline Self-Efficacy & 30 years-under & 120.852 & 2.058 & 116.797 & 124.907 \\
& 31- 40 years & 113.263 & 2.329 & 108.674 & 117.852 \\
& 41 - 50 years & 114.814 & 2.651 & 109.590 & 120.037 \\
& Above 50 years & 114.612 & 2.764 & 109.167 & 120.057 \\
\hline
\end{tabular}

Table 4: Estimated Marginal Means on Age

Table 4 shows that Chemistry teachers who are 30 years and under have high self-efficacy de towards inclusive education as shown by their high mean score of 120.852than Chemistry teachers of other age groups. To determine if the difference is significant, Hypothesis 2 was tested at 0.05 level of significance.

- $\mathrm{HO}_{2}$ : There is no significant influence of Age on Chemistry teachers' self-efficacy in implementing inclusive education.

Result in table 4 shows that there is a significant influence of Age on Chemistry teachers' self-efficacy in implementing inclusive education at .018 level, which is less than 0.05 level of significance. The null hypothesis is therefore rejected.

Also result in table 4 shows that there is no significant interaction between the gender and age of the Chemistry teachers in their self-efficacy in implementing inclusive education at .440 level of significance. This is above 0.05 level of significance.

\section{Discussion}

Result as presented in Table 2 shows that gender has a significant influence on Chemistry teachers' self-efficacy to inclusive education and it's in the favour of females. This could be attributed to the fact that females are naturally endowed with softness and empathy, understanding the thoughts, feelings or emotional state of another person. According to Akhtar (2008), positive emotions can boost one's confidence in one's skills and skill possession thus raise self-efficacy. These findings give credence to that of Ekwueme \& Umoinyang (2005), but at variance with Okonkwo (2012).

Furthermore, Table 4 reveals that the teachers' age had significant effect on self-efficacy in implementing inclusive education. The significant influence of age is in the favour of younger teachers (30years and below). This can be attributed to the fact that the concept of inclusive education is relatively new and the older teachers were done with schooling before its inception and resultantly do not know much about it. Having knowledge and experience in an inclusive classroom also significantly influenced teachers' attitude and self-efficacy towards inclusive education. Teachers with experience and knowledge showed more positive attitude and higher self-efficacy, as can be deduced from their higher mean attitude and mean efficacy scores in table 3 and 4, thus giving credence to Maddux (2005) report that self-efficacy beliefs develop as a result of information from resources such as experience among others.

Surprisingly, in a mild interaction between the researchers and the teachers, none of the teachers indicated to have received any form of training and this is very worrisome because it portrays danger and a serious threat to the achievement of the objectives of the inclusive education program. In addition to this lapse, the teachers reported that the experience and knowledge few of them possess were acquired informally. It seems teachers with positive attitude towards inclusive education were found to equally have a high efficacy in implementing inclusive education.

\section{Conclusion and Recommendation}

In as much as inclusive education is recommended by UNESCO and all stakeholders in education, it is evinced that not countries are ready for inclusive classroom teaching. Teachers have myriad of factors which invade their preparedness to implement inclusive education. demographic factors like age, gender and self-efficacy are some of the factors which affect inclusion in our classroom especially. Older teachers do not have effective skill and emotion to implement inclusive education. For any curriculum change to be explicitly implemented, teachers should be trained and made to understand the need for it. There is a need for the curriculum to be reviewed in such a way that it will incorporate the skills that will enable their products to effectively pursue the implementation of inclusive education in classroom.

Chemistry teachers should be educated on the importance and benefits of inclusive education. Male chemistry teacher should as well be enlightened on these benefits. This is due to the fact that research findings show that male Chemistry teacher show less positive attitude and self-efficacy in implementing inclusive education. It is imperative for all teachers to be well trained in other not to create a lacuna in the sphere of education.

Government should ensure that there is an adequate provision of support materials and service in actualizing inclusive education.

\section{References}

i. Alay, A. \& Triantoro, S., (2013). Effects of Self-Efficacy on Students' Academic Performance. Journal of Educational, Health and Community Psychology. 2(1) 22-30.

ii. Aliyu, A. J. \& Ndubuisi S. I., (2015). An empirical overview of the practicability of inclusive education in Kano State. National Journal of Inclusive Education. 3(1)147-155.

iii. Avisar, G., Reiter, S. \&Leyser, V., (2003). Principals view and practices regarding inclusion: the case of Israelis elementary school principals. European Journal of Special Needs Education. 18, 355-369

iv. Danmole, B. T. \& Femi - Adeoye, K. O., (2004). Effect of concept mapping techniques o senior secondary school students' achievement and retention in ecology concepts. Lournal of STAN. 39(1\&2), 31-37. 
v. Domenech, B. F., Abellan, R. L. \& Gomez, A. A. (2017). Self-Efficacy, Satisfaction and Academic Achievement: The Mediator Role of Students' Expectancy Value Beliefs. Front.Psycho.8:1193.doi,10-3389/fpsy.2017.01193

vi. Ekperi, M., UdeOnwuka, \& Wike, Nyejirime (2019). Teachers' attitudes as a correlate of students' academic performance in geography. International Journal of Research and Innovation in Social Sciences (IJRIS).111(1) $2454-6185$.

vii. Ekwueme, G. O. \& Umoinyang, I. E., (2005). Gender differences in mathematics: factors among secondary school students in calabar, cross - rivers state. 45 ${ }^{\text {th }}$ Annual Conference Proceedings of STAN. $224-228$.

viii. Ifeakor, A. C. (2005). Evaluation of commercially produced computer assisted instruction package for teaching secondary school chemistry. An unpublished Ph.D. thesis. Nsukka. University of Nigeria.

ix. Keremcoskun, Mustafa metin, Kenan bulbul \&Gulkaleh Yilmaz (2011). A study on developing an attitude scale towards multigrade classrooms for elementary school teachers. Procedia Social and Behavioural Sciences. 15 (2011), $2733-2737$.

x. Kielback, S., (2018). Inclusive education for all: Development of an instrument to measure the teachers' attitudes. Unpublished Ph.D. thesis Australia: Justus Liebig University Giessen.

xi. Mahat, M. (2008). The development of a psychometrically - sound instrument to measure teachers' multidimensional attitude towards inclusive education. International Journal of Special Education. 23(1), 82-92.

xii. Mari, J. S. (2002). Gender related differences in acquisition of formal reasoning schemata: pedagogical implication of teaching chemistry using power-based approach. JSTAN. 37(1\&2) 76-81.

xiii. MucellaUlug, MelisSeray, Ozden Alu Eryilmaz, (2011). The effects of teachers' attitudes on students' personality and performances. Procedia - Social and Behavioural Sciences. 30(2011) 738-742.

xiv. Mundy, K., (2016). 'Leaning in' on education for all. Comparative review. 60(1): 1-26.

xv. Newton, N., Carbridg, J., \& Johnson Y., (2014). Teachers perception of inclusive education and its implication for adult education in the Bahamas. Adult Education Research Conference Proceedings. 330-336.

xvi. Okonkwo, I. G. A., (2012). Effect of concept mapping and simulation-game teaching strategies on students achievement and interest in environmental concepts in chemistry. Unpublished Ph.D. Thesis Nsukka: University of Nigeria.

xvii. Okoye, F. O. \& Adirika, B. N., (2019). The challenges of implementing inclusive education for visually impaired undergraduates in Nigeria Tertiary Institutions. European Journal of Education Studies. 6 (2) 239-251.

xviii. Okuoyibi, J. M., (2001). An alternative education placement for exceptional children in Nigeria's new policy dispensation. Ibadan: Option Books.

xix. Olubukola, J. O., (2018). Teachers professional attitudes and students' academic performance in secondary schools in ilorin metropolis of Kwara State. E-journal of Education Policyhttp://nau.edu/COE/e-journal

xx. OlukaBerthy (2014). Instructional skill needs of teachers for inclusive classroom in primary schools in Ebonyi State. Unpublished Ph.D. thesis. Nsukka University of Nigeria.

xxi. Onuigbo, L. N., (2013). Regular school needs for creating an inclusive learning - friendly environment. International Journal of Research in Arts and Social Sciences. 5, 294-307.

xxii. Talmor, R., Reiter, S. \& Feigin, N. (2005). Factors relating to regular education teacher burnout in inclusive education. European Journal of Special Needs Education. 20(2), 215-229.

xxiii. U.N.E.S.C.O, (1990). World declaration on education for all. Paris. UNESCO.

xxiv. U.N.E.S.C.O, (1994). The Salamanca statement. Paris. UNESCO.

xxv. U.N.E.S.C.O, (2005). Guidelines for inclusion. Ensuring access to education for all. In Paris. UNESCO.

xxvi. U.N.E.S.C.O, (2015). Incheon declaration; Education 2030: Towards inclusive and equitable quality education and lifelong learning for all. In Paris. UNESCO.

xxvii. UN, (1948). Universal Declaration of Human Rights. In Paris. United Nations.

xxviii. UN, (2006). Convention on the rights of persons with disabilities. Retrieved from http://www.un.org/disabilities/documents/convention/convoptprot-e pdf.

xxix. Wilde, N. \& Anne H., (2019). The Influence of General Self-efficacy on the Interpretation of Vicarious Experience Information Within Online Learning. International Journal of Educational Technology in Higher Education. 16(26).

xxx. Wilmot, E. M. \& Otchey J. E., (2012). The contribution of attitude of students and teachers on Junior high school students' achievement in mathematics. African Journal of Educational Studies in Mathematics and Sciences. 10, 55-63. 